\title{
Like it or not? The differences between and success factors of sports providers' use of social networking sites
}

\section{Joris Corthouts, Astrid Denys, Erik Thibaut and Jeroen Scheerder*}

Policy in Sports and Physical Activity Research Group,

Catholic University of Leuven,

Leuven, Tervuursevest 101, Belgium

Email: joris.corthouts@kuleuven.be

Email: astrid.denys@me.com

Email: erik.thibaut@kuleuven.be

Email: jeroen.scheerder@kuleuven.be

*Corresponding author

\begin{abstract}
The current study seeks to analyse differences in the usage of social networking sites (SNSs) between different sports organisations in Flanders (Belgium), more particularly between sports federations (SFs), fitness centres (FCs), and local sports governing bodies (LSGBs). Second, this study aims to determine which factors make that Facebook posts of SFs, FCs, and LSGBs draw the attention of (potential) sports consumers, depicted by the number of 'likes' per post. For one month, an exploratory desk research on Facebook pages of 82 SFs, 154 LSGBs, and 118 FCs was conducted. The results demonstrate that: (a) significant differences exist in SNS usage between the three organisations; (b) posting atmosphere or feel-good content posts is, among others, beneficial for every sports providers' Facebook post. The results of the current study provide employees of sports organisations with information about how a successful SNS policy can be developed to gain attention of current and future sports participants.
\end{abstract}

Keywords: social networking sites; SNSs; social media; likes; post popularity; sports federations; local sports governing bodies; LSGBs; fitness centres; sport management; sport marketing.

Reference to this paper should be made as follows: Corthouts, J., Denys, A., Thibaut, E. and Scheerder, J. (2019) 'Like it or not? The differences between and success factors of sports providers' use of social networking sites', Int. J. Sport Management and Marketing, Vol. 19, Nos. 1/2, pp.56-79.

Biographical notes: Joris Corthouts graduated in 2017 as a Master in Physical Education and Kinesiology at the KU Leuven, Belgium. Currently, he prepares a $\mathrm{PhD}$ thesis with a focus on innovation within the voluntary non-profit sports sector as part of the Policy Research Centre on Sport 2017-2022.

Astrid Denys graduated in 2017 as a Master in Physical Education and Kinesiology at KU Leuven. After graduating, she completed a Postgraduate in Digital Marketing and Communication at the Ehsal Management School in Brussels. Nowadays, she works as a digital marketer for several companies. 
Erik Thibaut obtained his degree of Doctor of Kinesiology, KU Leuven in 2017. His research focus is mainly on the determining factors of the time and money that is spent on sports participation. He has published in multiple peer-reviewed journals, such as the Sport Management Review, the European Sport Management Quarterly and the International Journal of Sport Management and Marketing. Now, he is the coordinator of the Policy Research Centre on Sport 2017-2022, that performs policy related research regarding sports participation.

Jeroen Scheerder is a Professor in Sport Policy and Sport Sociology in the Department of Movement Sciences at the KU Leuven, Belgium. He is the Head of the Policy in Sports and Physical Activity Research Group. He was the President of the European Association for Sociology of Sport (EASS), was a Visiting Professor in Sport Sociology at the Faculty of Political and Social Sciences, Ghent University, Belgium, and co-founded both the European MEASURE and POLIS Research Networks that focus on sport participation and sport policy/sport politics respectively. $\mathrm{He}$ is the co-editor of Running across Europe: The Rise and Size of One of the Largest Sport Markets and Sport Policy Systems and Sport Federations: A Cross-National Perspective (both published by Palgrave Macmillan).

\section{Introduction}

In today's social media/internet era, it lies in the human nature to develop technologies that make it easier for us to communicate with each other (Dollinger, 2015; Ngai et al., 2014). Social media is a term to describe online tools that allow for sharing information and content on the web (e.g., video, images, text, news, and opinion), and participation and collaboration through social interaction between individuals as well as entities like organisations (Newson et al., 2009; Reyneke et al., 2011; Wallace et al., 2011). Worldwide, 2.46 billion people were active on social media in 2017, which accounts for approximately $71 \%$ of the internet users. The most popular social networking site (SNS) is by far Facebook, with over two billion monthly active users (Statista, 2017). As the number of active Facebook users in 2011 was 750 million (Wallace et al., 2011), this number has more than doubled since. Although the number most likely not double in the upcoming years, it is still expected that user numbers of SNSs will steadily increase. Scholars argue that the booming popularity of SNSs is due to unique characteristics such as their openness, participation, and sharing possibilities (Khan et al., 2014). Furthermore, while sports organisations are not able to control the traditional media, SNSs provide them with the opportunity to communicate messages in an unfiltered and direct way to the public (Miranda et al., 2014; Wallace et al., 2011).

In this regard, companies adopt SNS strategies in business and marketing strategies to construct a good reputation, shape an innovative company culture, strengthen change management initiatives, improve corporate strategy, gain a better competitive advantage, and facilitate communication with both their employees and customers (Michaelidou et al., 2011; Ratten, 2011; Roohani and Attaran, 2013; Torben, 2010). In this context, sports organisations also increasingly implement SNSs in their communication strategies. 
Accordingly, there has been a rise in research concerning social media usage within sports organisations. Abeza et al. $(2015,2017)$ for example found social media as an effective marketing tool to enhance customer/fan communication and relationships. Although a significant body of research has investigated SNS usage of professional sports teams (e.g., Miranda et al., 2014; Pronschinske et al., 2012) and national sports federations (SFs) (e.g., Abeza and O'Reilly, 2014; Belot et al., 2016), little research has focussed on non-profit and/or local sports organisations. Nevertheless, Mahan et al. (2015) indicate that SNSs can both 'push' and 'pull' people into a more physical active and satisfying lifestyle, indicating that SNSs are a potential interesting tool to increase sports participation rates. In this context, there was a positive relationship between the use of running-related SNSs, running and mental health, and a positive mediating link between running involvement and SNSs, which may indicate supra sportive intentions (e.g., 'friending' other athletes on Facebook).

The current study aims to contribute to the underexposed research regarding SNS usage of non-profit and/or local sports organisations. It seeks to identify differences between three sports providers in Flanders, the north speaking part of Belgium. These three sports providers are:

1 SFs

2 local sports governing bodies (LSGBs)

3 fitness centres (FCs).

Moreover, they represent three of the main sports providers in Western European countries. Furthermore, an innovative research method will be applied to investigate this topic. Miranda et al. (2014) differentiate between two methods to evaluate SNS usage, i.e., attribute and process-based methodology. The former refers to the objective evaluation by independent judges or the subjective evaluation by users and the latter refers invokes that the quality of SNSs is assessed through a sequence of processes that occur while surfing on the SNS in question. While mostly descriptive, non-systematic analyses on the use of SNSs are put forward in the sports research domain (de Vries et al., 2012; Eagleman, 2013; Miranda et al., 2014; Sabate et al., 2014; Schultz, 2016), the current study will employ an objective attribute-based method to test, through multivariate analyses, the theoretical foundations on characteristics influencing post popularity.

In sum, this study intends to fill the gap in sports marketing communication literature by providing evidence on how different sports organisations use SNSs, and by examining determining characteristics of post popularity, i.e., the ratio of the number of 'likes' per post and the number of 'likes' of the Facebook page in question, per sports provider.

The paper is structured as follows: to start, a literature review on social media and sport, and on post popularity is provided in Section 2; subsequently, the methodology is described in Section 3; as a third step, results are presented, interpreted in Section 4, and discussed in Section 5; finally, in Section 6, conclusions and limitations of this research are described. 


\section{Literature review}

\subsection{Typology of SNS}

Throughout human history, evolutions in technology have made it easier to communicate with each other (Carton, 2009). One of the first, early, basic forms of social media, in the 1970s, were the virtual playing worlds with online chat and interactive fiction (Edosomwan et al., 2011). Despite its relative success, most of the SNSs that have been created in the 1990s, such as Six Degrees and Black Planet do not sound as familiar as SNSs that were invented after 2000 (e.g., Facebook, Twitter, Instagram, and LinkedIn). The popularity of the latter SNSs is mostly due to the transformation of the interaction processes and mechanisms. Individuals who share the same interest in music, education, movies, friends, sports, etc., are able to connect with each other more easily (Edosomwan et al., 2011).

To map the large amount of social media literature, Abeza and O'Reilly (2014) divide the different social media into five categories:

1 social networks

2 content communities

3 forums and bulletin boards

4 blogs

5 content aggregators.

Kaplan and Haenlein (2010) use a more detailed technique to classify social media, based on two axes: one axis for the social presence/media richness and another for self-presentation/self-disclosure. This categorisation results into six distinct categories:

1 blogs

2 collaborative projects (e.g., Wikipedia)

3 virtual social worlds (e.g., Second Life)

4 virtual game worlds

5 content communities (e.g., YouTube)

6 SNSs.

Additionally, Kietzmann et al. (2011) emphasised the different peculiarities of each social medium in their 'honeycomb of social media'.

Based on these classifications, it can be noticed that Facebook, Twitter, Instagram and LinkedIn are classified as SNSs. This signifies the various forms of social media and SNSs as a subdivision of it. 


\subsection{Conceptual framework and hypotheses development}

Figure 1 represents the conceptual framework of this study. The first research question investigates whether SNS usage differs between the three sports providers. SNS usage is analysed via the presence of an account on Facebook, Twitter, Instagram and LinkedIn, and via post frequency, content, layout and page popularity. The second research question argues that the abovementioned independent variables can influence post popularity. Following, both research questions and corresponding hypotheses are illustrated in Figure 1, and they will be further explained in the next paragraphs.

Figure 1 Hypothetical model

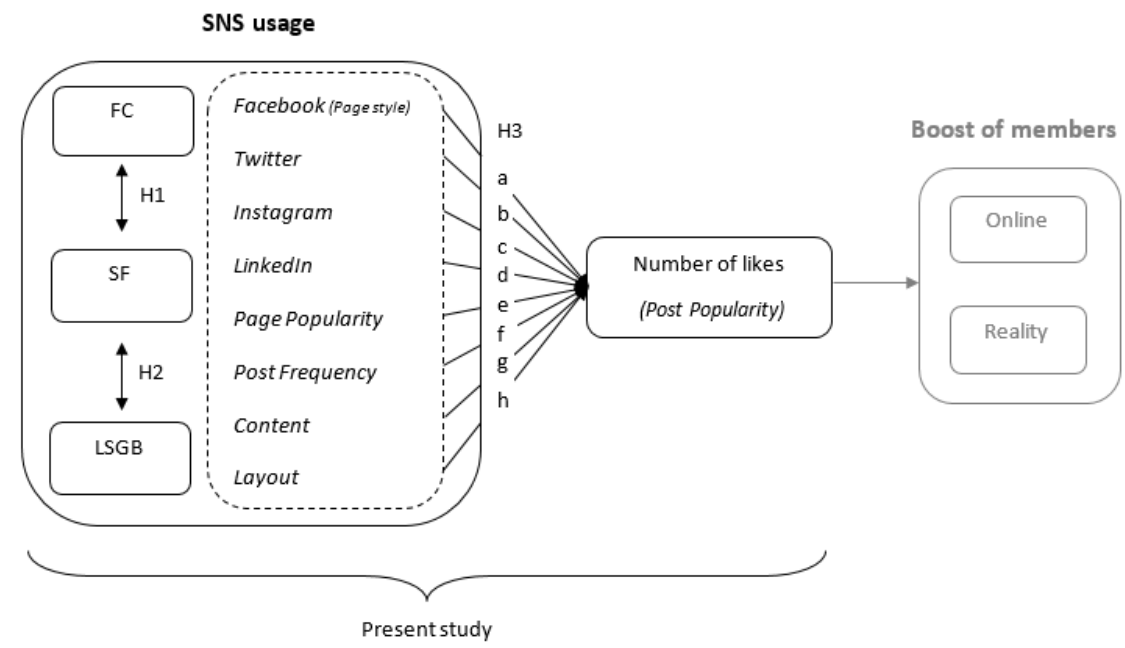

\subsubsection{Sports organisations' use of SNSs}

As mentioned in the introduction, SNSs play an important role in the field of modern sports, where they are used to strengthen the traditional one-way marketing channels, such as radio, television, posters, etc., by means of two-way communication (Pegoraro, 2014). Consequently, research concerning social media usage within sports organisations is growing. Today, studies on this topic have been conducted from different angles. Most authors focus on the nature of social media (Abeza et al., 2015). In this matter, a distinction can be made between scholars who focus on the use of social media at an organisational meso-level within professional teams (Miranda et al., 2014; Pronschinske et al., 2012) or national SFs (Abeza and O'Reilly, 2014; Belot et al., 2016) versus scholars who investigate the micro-level motives and attitudes of users and consumers (Schubert and Seyffert, 2017). National SFs and professional teams have been the most common subject of investigation. Additionally, SNS use within non-profit and/or local sports organisations have seldom been subject to study. Furthermore, the various sports organisations have been studied using different definitions of innovations and research methodologies. This makes a comparison impossible and provides the authors of the current study with the incentive to formulate following research question:

RQ1 What are the differences between SFs, LSGBs and FCs' SNSs usage? 
As illustrated by Scheerder et al. (2011), the profit intentions differ between the three sports sectors. Whereas SFs target social profit such as social inclusion, LSGBs aim to produce public profit. Finally, FCs are economic oriented sports providers that aim to increase their sales revenues. Yet, although their profit orientations and organisational characteristics are not the same, they do experience competition from one another (Schubert and Seyffert, 2017). To cope with the highly competitive sports environment, sports organisations strive to innovate by, amongst others, committing and engaging with their community through social media in order to retain, and preferably augment it. A condition for retaining or recruiting members is placing interesting messages on one's own SNS profile. In doing so, people will (continue to) like the organisations' posts, as a result of which the message is also spread among peers, who in turn can like the page and posts themselves, and so forth (Sabate et al., 2014). In light of the above, an SNS can be viewed as an interesting relationship builder and as a marketing/business tool (Abeza and O'Reilly, 2014; Lee, 2011; Waters et al., 2009). After all, it is often cited that word-of-mouth is the most efficient and rewarding form of advertising. SNSs are, in fact, online versions of word-of-mouth-advertising because of their ability to foster interactive communication. Moreover, people tend to trust SNSs, and in particular, recommendations, i.e., 'liked' posts, by peers, more than commercial advertising (Hailey, 2010; Lee, 2011; Sabate et al., 2014). Indeed, Ramadani et al. (2014) found a strong significantly positive relationship between trust of social media and users' attitude towards it, or, as cited by Zuckerberg: "People influence people. Nothing influences people more than a recommendation from a trusted friend. A trusted referral influences people more than the best-broadcast message. A trusted referral is the Holy Grail of Advertising" (Schonfeld, 2007). In this context, an SNS can be interpreted as the most cost-effective method for marketing activities (Edosomwan et al., 2011; Lee, 2011; Paridon and Carraher, 2009; Shinder, 2012), and for reaching customers on a personal level on a daily basis (Eagleman, 2013; Witkemper et al., 2012). These purposes are often investigated from a relationship marketing point-of-view. Abeza et al. (2017), for example, studied how professional sports organisations implemented Twitter into their relationship marketing processes, with a particular focus on the three core components of the theoretical framework of relationship marketing, i.e.:

1 communication

2 interaction

3 value.

Herein, communication refers to the type of content posted, interaction indicates the way users become engaged in dialogue on social media, and value encompasses the added meaning that emerges through the interplay of communication and interaction. Notwithstanding the fact that most organisations recognise SNSs' benefits, such as their free-of-charge use, even most professional sports teams prove to be unable to manage the full opportunity of social media (Miranda et al., 2014).

Within the research on sport and social media, SFs or national sports organisations and major professional organisations are the most commonly researched subjects. The use of social media, especially Facebook and Twitter, appears to be the norm for national sports organisations. Within this sector, Eagleman (2013) analysed the use of and motivations by employees towards SNSs in national governing bodies (NGBs) of sport. 
All participating NGBs had a Facebook, $98.4 \%$ a Twitter, and $12.9 \%$ a LinkedIn profile. Although the introduction of social media, and other technological advances, have innovated how people view or practice sport, the use of social media by sports organisations is more often viewed as the rule rather than the exception, and thus, cannot be stigmatised as innovative behaviour. On the other hand, the way in which organisations use SNSs can be regarded as entrepreneurial, for example, when new advertising and marketing methods are adopted through these media (Ratten, 2011). From this perspective, Eagleman (2013) found that NGBs used Facebook more as a channel for communication purposes, rather than as a tool to realise marketing objectives, such as sponsorship recruitment, and hence, were not genuinely entrepreneurial. This finding was supported by Abeza and O'Reilly (2014) who found that 24 Canadian NSOs use Facebook and Twitter to communicate, but to a lesser extent to interact with fans. With regard to the layout and content, mainly photos and/or videos were posted to disseminate information about the organisation and to enter into dialogue with fans. To a lesser extent, promoting and sponsorship-related content was posted (Abeza and O'Reilly, 2014; Eagleman, 2013; Schubert and Seyffert, 2017). In their case study, Thompson et al. (2014) examined the implementation of a social media strategy for a national sports organisation Tennis New Zealand. In their findings, they highlight, amongst other things, how promotion posts can increase fan awareness. Additionally, the authors argue that post content should alternate adequately, so that (potential) fans have a lot of variety. Even at an international level and in one of the most popular sports (i.e., football; FIFA), SNSs appear to be used more as a one-way means of communication (Belot et al., 2016). Moreover, within their Twitter communication content, more than half of their posts covered stakeholder news, i.e., information associated with 'famous' elite players.

While the importance of social media is often underlined for the main players in the commercial sports sector, the role of SNSs in FCs has seldom been studied. Nonetheless, aiming to explore the relationship of annual turnover and engagement on SNSs of FCs, Garcia-Fernandez et al. (2017) found that FCs also use Facebook (70\%) and Twitter $(51 \%)$ the most, albeit less than SFs do.

Given the abovementioned findings from literature and considering the level of analysis of both sports providers (i.e., regional for SFs and local for the FCs), the following hypothesis can be formulated:

H1 SFs, in comparison to FCs, are more often present on Facebook (a), Twitter (b), Instagram (c) and LinkedIn (d), have a higher popularity of their Facebook page (e), post more frequently on Facebook (f), post more elite sport focused content (g), and post more photos as layout of their posts (h).

From a public-sector perspective, literature on sport and social media at a local level is scarce. In contrast to LSGBs, local governments, i.e., municipalities, have been subject to social media research. In connection to the latter, Agostino (2013) established that $92 \%$ and $31 \%$ of municipalities had an 'unofficial' Facebook and Twitter account. Analogously, Facebook was used by all 156 US cities involved in the research of Bennet and Manoharan (2016), notwithstanding that only $20 \%$ had a written policy. Research in Flanders pointed out that $95 \%$ of 119 Flemish municipalities declared to employ social media. In particular, a quantitative analysis showed that $73 \%$ of all local governments had a specific corporate Facebook account, and 65\% a Twitter account (Desmet and Bougrea, 2016). In comparison with the Netherlands, Flemish municipalities post less 
frequently, use both SNSs more as a broadcast channel and 'push' general content to their fans, instead of interacting with them. Finally, local governments were found to have on average 21.032, which would correspond with $10 \%$ of the inhabitants reached, while Facebook has the possibility to reach over $50 \%$ of the inhabitants (Desmet and Bougrea, 2016).

H2 LSGBs, in comparison to SFs, are less present on Facebook (a), Twitter (b), Instagram (c), and LinkedIn (d), have a lower popularity of their Facebook page (e), post less frequently on Facebook ( $\mathrm{f}$ ), post more general information content $(\mathrm{g})$, and post less photos as layout of their posts (h).

\subsubsection{Post popularity on Facebook}

As of June 30, 2017, Facebook counts more than two billion monthly active users (Facebook, 2017). It operates like a personal website where users 'create' their own content by filling out personal information, posting pictures and texting comments about their activities, etc. Furthermore, Facebook users can correspond privately with their friends, write something on a friends' page ('wall') or appoint and identify ('tag') someone in a photo. This information is shared with the community but can be restricted to a certain amount of people (Chia-chen and Bradford, 2013).

Currently, only a few studies have researched the specific use of SNSs, particularly Facebook, in the field of sport. Like Waters et al. (2009) and Pronschinske et al. (2012) investigated the impact of disclosure, involvement, information dissemination and authenticity as SNSs communication cues pertaining to the number of 'likes' on a professional sports team's Facebook page, referred to as page popularity in this study. Contrarily, a lack of literature exists on post popularity in a sports context. Post Popularity is not always conceptualised in the same way, but does usually contain the same theoretical foundation. For example, Miranda et al. (2014) refer to popularity as the number of followers of firms' pages and use the term interactivity when identifying post level characteristics, such as number of 'likes' and comments per post. Distinct from the denomination, there is general agreement that the number of 'likes' per post is an important variable in determining the marketing practices of organisations and the subsequent commitment of users (Sabate et al., 2014). Since research into post popularity in a sports context is scarce, this study broadens its scope, as it also takes into account international commercial brands (de Vries et al., 2012), the travel (Sabate et al., 2014) and apparel industry (Schultz, 2016) for answering the following research question:

RQ2 Which are the determining characteristics of Post Popularity on Facebook?

First, studies have not yet investigated the impact of the use of other SNSs on Facebook's post popularity. Sharpe et al. (2017) point out that each SNS needs a tailored approach and managing multiple pages is time consuming. However, it is evident that customers or fans, based on their personality (Hughes et al., 2011) and profession (Santana and Hopp, 2016), do not always prefer Facebook as their primary SNS. In this regard, it could be useful for a sports organisation to focus on more than one SNS. Assuming most organisations recognise the importance of being present on different SNSs (see also RQ1) and have the time to do so, it is presumable that disseminating information on more than one SNS could be beneficial for attracting users to 'like' their organisation's Facebook page as well. Hence, the following hypothesis is formulated: having an account on 
Twitter [(H3(a)], Instagram [H3(b)] or LinkedIn [H3(c)] is a positive determinant for post popularity on Facebook.

Second, the number of followers is a vital factor in post engagement. In that regard, Sabate et al. (2014) found that the number of followers has a significant positive consequence on the number of 'likes'. Therefore, an increase in page popularity is considered a significant determinant [H3(d)].

Third, the specific timing of the post is found to positively influence the number of 'likes'. Facebook's modus operandi ensures the last posted messages will appear on top of the page, and as a result, older posts are placed beneath. Therefore, the organisations that post more frequently are less visible and will receive less 'likes'. Indeed, de Vries et al. (2012) found that the longer a post was positioned at the top of the Facebook page, the more 'likes' it would get. In the view of post frequency, Eagleman (2013) also stated there is a thin line between too many updates or not enough. Consequently, it can be expected that the post frequency will have a significant (negative) effect on post popularity $[\mathrm{H} 3(\mathrm{e})]$.

Fourth, in terms of media type or layout, a page moderator can post either a:

1 status

2 photo

3 video

4 shared post

5 a link (Wallace et al., 2011).

These subcategories represent different degrees of vividness and interactivity (Pletikosa Cvijikj and Michahelles, 2013). Whereas, vividness can be understood by the richness of a post in terms of stimulating different senses within people, interactivity, in turn, refers to 'the degree to which users can influence the form and content of the media environment' [Pletikosa Cvijikj and Michahelles, (2013), p.847]. A video is for example more vivid than a photo because it stimulates more senses (i.e., sight and hearing), and a link creates less interactivity than a contest or question (de Vries et al., 2012; Lovejoy et al., 2012; Schultz, 2016). Overall, findings demonstrate a significant positive effect in 'like'-ratio for (high-vivid) videos (Pletikosa Cvijikj and Michahelles, 2013; Sabate et al., 2014; Schultz, 2016). Otherwise, low-vivid photos seem to drive the number of 'likes' as well (Pletikosa Cvijikj and Michahelles, 2013; Rahman et al., 2016; Schultz, 2016). Therefore, this study hypothesises that photos have a positive effect on post popularity [H3(f)].

Finally, content can also influence post popularity (Pletikosa Cvijikj and Michahelles, 2013). Content is mainly divided into an information and entertaining category (de Vries et al., 2012), while Pletikosa Cvijikj and Michahelles (2013) added a remuneration category. The aforementioned studies found contrary results: both information and entertaining related posts determined the 'like'-ratio positively in Pletikosa Cvijikj and Michahelles' (2013) study, while no influence was found within the study of de Vries et al. (2012). Other scholars, such as Schultz (2016), opt to divide content into different types of brand post topics (e.g., promotion, product, statement, etc.). Here, product and coverage-content have a significant positive influence on post popularity. Coverage is described as, 'reports on events, such as photo shoots, etc.' [Schultz, (2016), p.4], and 
thus can be compared to this study's content category 'atmosphere'. Therefore, it is suggested $[\mathrm{H} 3(\mathrm{~g})]$ that 'atmosphere' content have a positive influence on post popularity.

In summary:

H3 The popularity of posts by SFs, LSGBs and FCs are positively influenced by having a profile on Twitter (a), Instagram (b), LinkedIn (c), an increase of page popularity (d), posting low-frequently (e), posting photos (f) with atmosphere related content (g).

In turn, an increase in post popularity can lead to an increase in the number of members, both on and offline (Mochon et al., 2017). As reflected in Figure 1, this does not fall within the scope of this study. Nevertheless, other researchers have examined this link. In general, findings suggest that 'liking' leads to a broader consumer and network attention (Naraine and Parent, 2016), and can influence consumer's buying intentions (John et al., 2017). However, Seng and Keat (2014) state that the act of merely liking a brand's Facebook page will not lead to real-life consumption.

\section{Data and method}

A content analysis, i.e., the analysis of documents and texts, whether printed or visual, seeking to quantify content in terms of predetermined categories and in a systematic and replicable manner (Parganas et al., 2015; Pinto and Yagnik, 2017), was conducted on each sports provider's SNSs. This analysis was carried out by two researchers, each responsible for half of the data collection.

The research sample comprises and differentiates sports providers of the commercial, the public and the federated sports sector.

As mentioned above, the current study focuses on sports organisations in Flanders (Belgium). The organisation of sports in Belgium differs from other countries in the composition of its governing bodies. Instead of being nationally organised, in Belgium, sport is a regional competence (Scheerder et al., 2011). Thus, this study analysed all 82 Flemish licensed SFs from the first until the 30th of March 2016.

Secondly, an extensive web analysis on the LSGBs and FCs was conducted throughout the month of November 2016. On the public level, LSGBs provide sports services for inhabitants of their municipality, though the approach and organisation per municipality differs, ranging from an exclusive, autonomic sports policy service to a one-person LSGB (van Poppel et al., 2016). A representative sample of 154 out of 308 LSGBs, based on a classification of 16 socio-economic categories (Dexia, 2007) has been randomly selected and analysed.

As prominent actors in the commercial sports market, FCs are also included. The representative sample of 118 out of $453 \mathrm{FCs}$ is based on the definition from the Social-Economic Council of Flanders as used by Scheerder and Vos (2010) in their Flemish fitness panel.

Importantly, posts were only analysed one week after their publication date due to possible delayed user interaction (Sabate et al., 2014). Because SNSs are vibrant social media, a time span of a week can be considered sufficient.

Figure 2 illustrates how the content analysis was managed and which variables were assembled for each Facebook page. Table 1 provides detailed information of these 
variables. The web content analysis initially examined whether SFs, LSGBs and FCs were active on Facebook (ID 1 in Table 1). Likewise, the presence of sports organisations on Twitter, LinkedIn and Instagram were also investigated. The variables numbered 2 (layout) and 3 (content) are categorical variables, which have been codified as dummy ones in order to fit with linear regression models.

Concerning the variable layout, five subcategories are distinguished. Notably, when the post consists of more than one subcategory, the one with the highest number is chosen.

The other categorical post variable is content, which is divided into ten groups. With regard to the content, the current study replicates Belot et al. (2016), Schultz (2016) and Williams et al.'s (2014) procedure in distinguishing different types of brand post topics. Table 1 provides one example for each category.

The above-mentioned categorical variables, layout and content, can be designated as subjective. In order to establish a substantial understanding of the coding procedure, agreement between the coders, and a reliable dataset prior to the data collection, a pre-test inter-coder reliability test was conducted through a Cohen's kappa test (Wallace et al., 2011), measuring the agreement between the coders while taking the agreement, which is obtained by chance alone (i.e., percent agreement; see for example McHugh, 2012) into consideration. In contrast to layout and content, the other variables, such as page popularity and post frequency, do not require an estimation on the part of the observer and were therefore not implemented in the pilot reliability test.

Figure 2 Variables collected from Facebook analysis (see online version for colours)

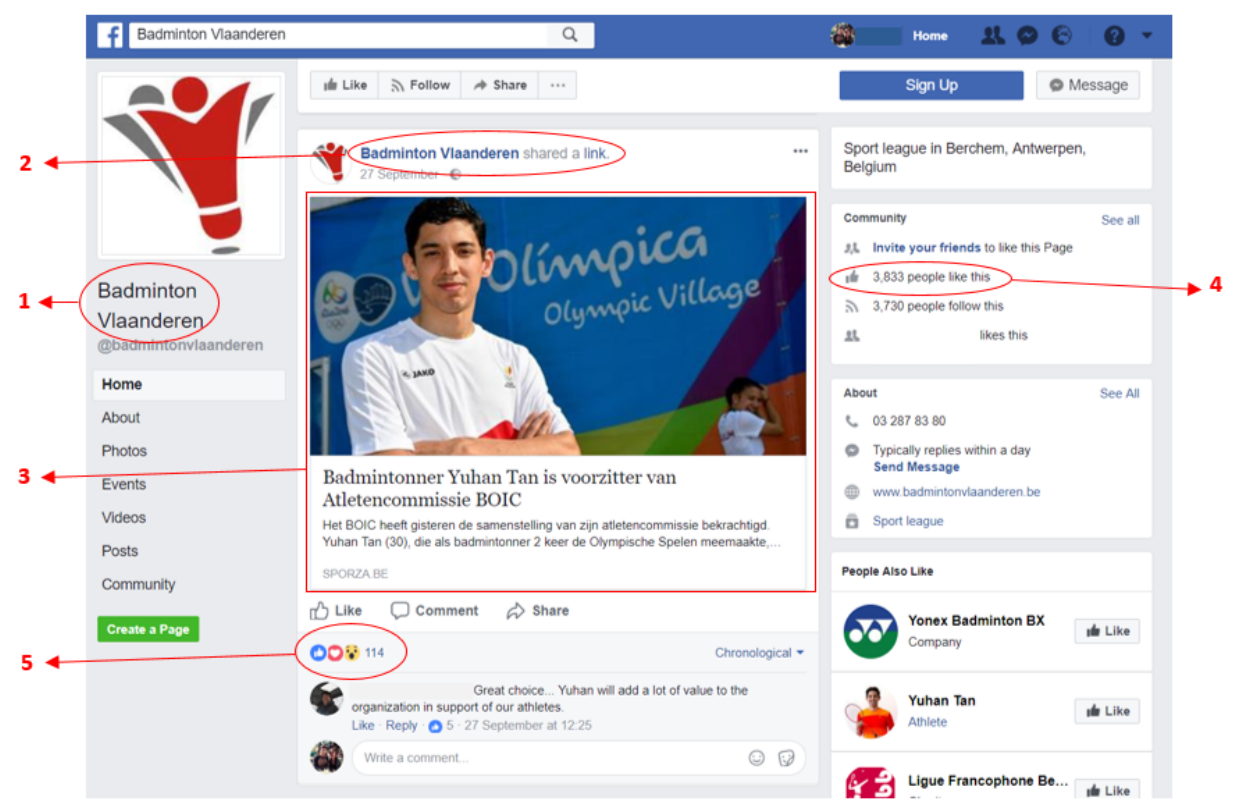

Notes: Legend: 1: Facebook profile; 2: layout; 3: content; 4: page popularity; 5: post popularity.

Source: Facebook (2017) 
Table 1 Operationalisation of the variables

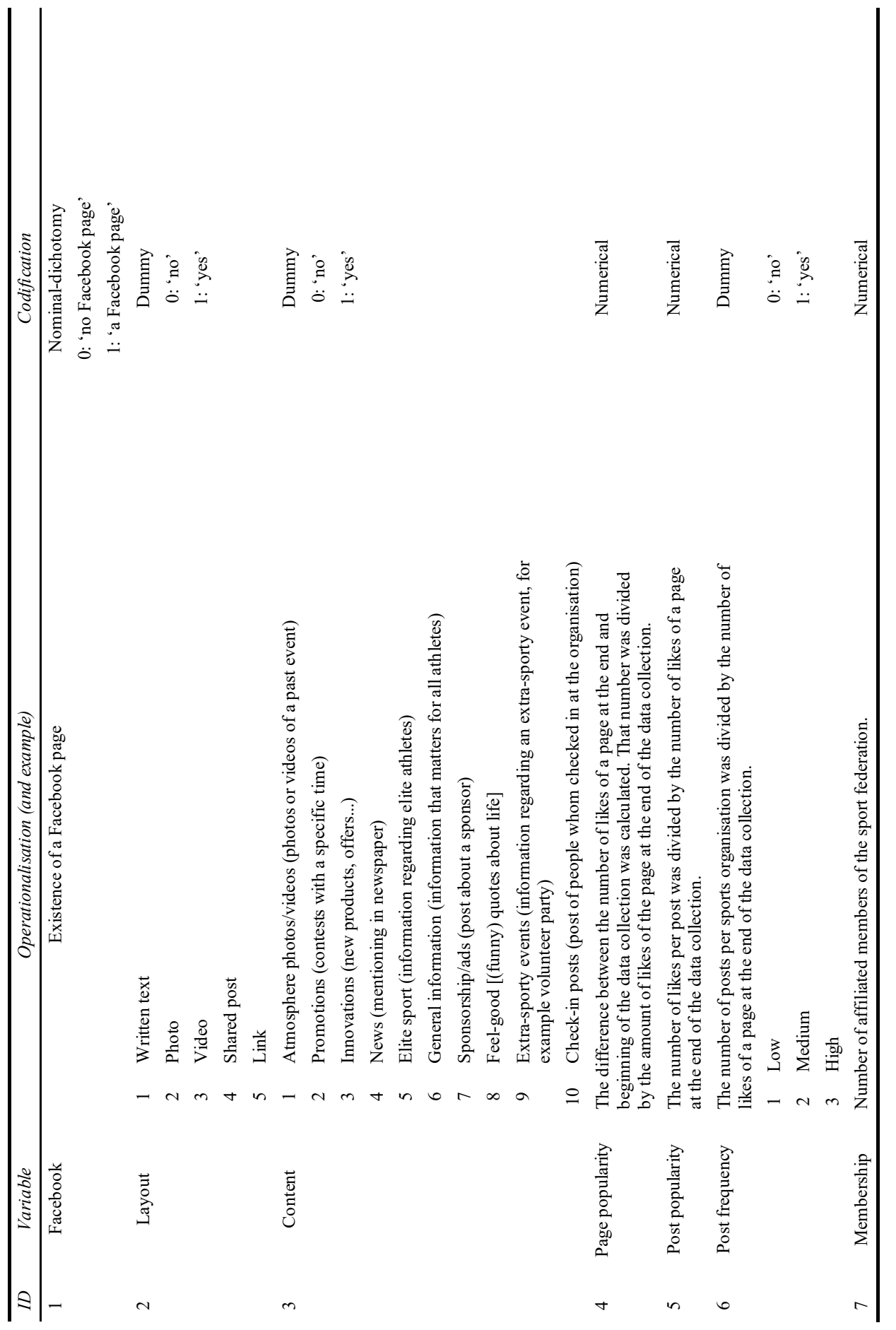


In light of the above, two weeks before the start of the data collection, the two coders collected data on the same content. The pilot subsample consisted of corresponding organisations of each sector from the original sample. The coders collected data following a predetermined codebook that was composed of variables based on expert opinions and literature review. A Cohen's kappa test indicated a substantial acceptable inter-rater agreement for both variables. In such, layout had a Cohen's kappa of 0.74 and content of 0.77 , which falls close to the cut-off value of .80 for excellent agreement and within the range of .60 to .80 for substantial good agreement (Cohen, 1960; Wallace et al., 2011; Watson and Petrie, 2010). Moreover, both variables had a percent agreement of $80 \%$. From a theoretical insight, the benefit of conducting a pre-test inter-coder reliability test is that, based on above analysis, the authors' codebook was further ameliorated. A practical reason for this test is that it allows the researchers to divide the coding work between the two different coders (Neuendorf, 2002).

In addition, two more variables are not visible in Figure 2, but are described in Table 1: post frequency and membership. As shown, post frequency is divided into three groups, and membership was only investigated for SFs.

As illustrated in Table 2, the current study tests the hypotheses by using chi-square tests, Kruskal-Wallis ${ }^{1}$ analyses and linear regressions.

Table 2 Overview of the statistical analyses

\begin{tabular}{lcc}
\hline Dependent variable & Statistical method & Independent variables \\
\hline Characteristics $^{\mathrm{a}}$ & Chi square & $/$ \\
$\begin{array}{l}\text { Post popularity and } \\
\text { page popularity }\end{array}$ & Kruskal-Wallis (post hoc Bonferroni) & Sector \\
Post Popularity & Multiple linear regression & Descriptive variables $^{\mathrm{b}}$ \\
\hline
\end{tabular}

Notes: ${ }^{a}$ Facebook, Twitter, Instagram, LinkedIn, layout and content; ${ }^{b}$ Facebook, Twitter, Instagram, LinkedIn, page popularity, post frequency, layout, content, and membership SF.

\section{Results}

\subsection{Differences in SNS usage (RQ1)}

Table 3 lists the proportion of SNS accounts per sports provider. Overall, the results clearly demonstrate differences within SNS usage. Concerning the organisations' presence on the four different SNSs, only LinkedIn is used equally by the three sports providers. However, the proportions of other SNS profiles differ between the sectors; in line with H1(a) and H1(b), FCs have both less Facebook (76.7\%) and Twitter (14.4\%) profiles. Noticeably, LSGBs have more profiles on Instagram $(34.4 \%)$ than LinkedIn $(29.2 \%)$, while our findings show that this is the inverse with SFs and FCs.

Next, also differences in Facebook posts' characteristics can be deduced from Table 4. In terms of layout, it is clear that 'photos' are the most prevalent layout for LSGBs $(47 \%)$ and FCs $(51.7 \%)$. Not for SFs, where the layout 'link' mainly occurs (38.9\%). 
Table 3 Frequencies (in \%) and descriptive statistics of the organisational characteristics for the SFs, LSGBs and FCs

\begin{tabular}{|c|c|c|c|c|}
\hline $\begin{array}{l}\text { Organisational } \\
\text { characteristics }\end{array}$ & $\begin{array}{c}S F S \\
(N=82) \\
\text { Perc. }(\%)\end{array}$ & $\begin{array}{c}L S G B S \\
(N=154) \\
\text { Perc. }(\%)\end{array}$ & $\begin{array}{c}F C s \\
(N=118) \\
\text { Perc. }(\%)\end{array}$ & Sign. \\
\hline Facebook & & & & $* *$ \\
\hline Yes & $87.8_{\mathrm{a}}$ & $86.4^{1}$ & $76.7_{\mathrm{b}}$ & \\
\hline Twitter & & & & $* * *$ \\
\hline Yes & $47.6_{a}$ & $79.9_{b}$ & $14.4_{c}$ & \\
\hline \multicolumn{5}{|l|}{ LinkedIn } \\
\hline Yes & $18.3_{\mathrm{a}}$ & $29.2_{\mathrm{a}}$ & $19.5_{\mathrm{a}}$ & \\
\hline Instagram & & & & $* * *$ \\
\hline Yes & $11.0_{\mathrm{a}}$ & $34.4_{b}$ & $15.3_{\mathrm{a}}$ & \\
\hline
\end{tabular}

Notes: Chi square test: $*=$ significant at $p<.05 ; * *=p<0.01 ; * * *=p<0.001$. Each subscript letter denotes a subset of sector categories whose column proportions do not differ significantly from each other at the .05 level. ${ }^{1} 37 \%$ of the Facebook profiles of LSGBs were general Facebook profiles of the municipality that posted LSGB-related content.

Table 4 Frequencies (in \%) and descriptive statistics of the Facebook posts' characteristics for the SFs, LSGBs and FCs

\begin{tabular}{lcccc}
\hline $\begin{array}{l}\text { Facebook posts } \\
\text { characteristics }\end{array}$ & $\begin{array}{c}S F S \\
(N=1491)\end{array}$ & $\begin{array}{c}\text { LSGBS } \\
(N=534)\end{array}$ & $\begin{array}{c}F C S \\
(N=663)\end{array}$ & Sign. \\
\hline Perc. $(\%)$ & Perc. $(\%)$ & $\left.* * *)^{\circ}\right)$ & \\
Written text & $10.8_{\mathrm{a}}$ & $7.1_{\mathrm{b}}$ & $5.1_{\mathrm{b}}$ & \\
Photo & $30.5_{\mathrm{a}}$ & $47.0_{\mathrm{b}}$ & $51.7_{\mathrm{b}}$ & \\
Video & $3.6_{\mathrm{a}}$ & $4.5_{\mathrm{a}, \mathrm{b}}$ & $6.3_{\mathrm{b}}$ & \\
Shared post & $16.1_{\mathrm{a}}$ & $24.5_{\mathrm{b}}$ & $20.5_{\mathrm{b}}$ & \\
Link & $38.9_{\mathrm{a}}$ & $16.9_{\mathrm{b}}$ & $16.4_{\mathrm{b}}$ & \\
Content & & & & \\
Atmosphere & $19.2_{\mathrm{a}}$ & $31.3_{\mathrm{b}}$ & $16.3_{\mathrm{a}}$ & \\
Promotions & $3.0_{\mathrm{a}}$ & $0.9_{\mathrm{b}}$ & $6.0_{\mathrm{c}}$ & \\
Innovations & $4.7_{\mathrm{a}}$ & $9.7_{\mathrm{b}}$ & $4.2_{\mathrm{a}}$ & \\
News & $6.0_{\mathrm{a}}$ & $4.7_{\mathrm{a}}$ & $1.2_{\mathrm{b}}$ & \\
Elite sport & $28.2_{\mathrm{a}}$ & $0.7_{\mathrm{b}}$ & $0.0_{\mathrm{b}}$ & \\
General information & $26.7_{\mathrm{a}}$ & $41.0_{\mathrm{b}}$ & $27.9_{\mathrm{a}}$ & \\
Sponsorship/ads & $1.1_{\mathrm{a}}$ & $0.7_{\mathrm{a}}$ & $1.7_{\mathrm{a}}$ & \\
Feel-good & $8.5_{\mathrm{a}}$ & $5.8_{\mathrm{b}}$ & $38.1_{\mathrm{b}}$ & \\
Extra-sporty events & $2.6_{\mathrm{a}}$ & $4.9_{\mathrm{a}}$ & $4.6_{\mathrm{a}, \mathrm{b}}$ & \\
Check-in posts & $0.0_{\mathrm{a}}$ & $0.2_{\mathrm{a}}$ & $0.0_{\mathrm{a}}$ & \\
\hline
\end{tabular}

Notes: Chi square test: $*=$ significant at $\mathrm{p}<.05 ; * *=\mathrm{p}<0.01 ; * * *=\mathrm{p}<0.001$. Each subscript letter denotes a subset of sector categories whose column proportions do not differ significantly from each other at the .05 level. 
Table 5 Kruskal-Wallis test of the page popularity and post popularity of Facebook for the different sectors

\begin{tabular}{lccccc}
\hline \multirow{2}{*}{ Variable } & \multicolumn{2}{c}{ Page popularity } & & \multicolumn{2}{c}{ Post popularity } \\
\cline { 6 - 7 } \cline { 5 - 6 } & $N$ & Mean rank & & $N$ & Mean rank \\
\hline Sector & 72 & $181.72_{\mathrm{a}, \mathrm{b}}$ & & 1491 & $1463.59_{\mathrm{c}, \mathrm{d}}$ \\
$\quad$ Sports federations & 133 & $132.02_{\mathrm{a}}$ & & 534 & $1143.45_{\mathrm{c}}$ \\
$\quad$ Local sports & & & & \\
$\quad \begin{array}{l}\text { governing bodies } \\
\text { Fitness centres }\end{array}$ & 87 & $139.48_{\mathrm{b}}$ & & 663 & $1238.61_{\mathrm{d}}$ \\
\hline
\end{tabular}

Notes: ${ }^{a, b, c, d}$ mean rank difference between the sub-variables of the variable is significant for the same letter at the 0.05 level (2-tailed). Both page popularity and post popularity are significant at level $\mathrm{p}<.001$.

On the content side of the posts, the most common content for SFs is 'elite sport' related with $28.2 \%$, followed by 'general information' (26.7\%). The 'general information' posts are most prevalent in posts of LSGBs, with $41.0 \%$. FCs, in turn, post 'feel-good' posts the most $(38.1 \%)$, as for the SFs and LSGBs this amount is only $8.5 \%$ and $5.8 \%$, respectively.

The findings above are partially in contrast to H1. SFs are relatively less often present on Instagram (c) and LinkedIn (d), although not significant. However, in accordance to H1, SFs have more accounts on Facebook (a) and Twitter (b), they post more than FCs (f), post mostly 'elite sport' content, and the layout of their posts are mostly 'photos' (h).

Contrarily to H2, it can be concluded that SFs and LSGBs are similarly represented on Facebook (a). For Twitter (b), Instagram (c) and LinkedIn (d), the results show that SFs have less active accounts. Aligned with $\mathrm{H} 2(\mathrm{f})$, SFs do post more.

Table 5 illustrates the results of the Kruskal-Wallis analysis. It is found that SFs' page popularity median is significantly higher than is the case for LSGBs and FCs. Thus, $\mathrm{H} 1(\mathrm{e})$ and $\mathrm{H} 2(\mathrm{e})$ can be confirmed.

The post-hoc analysis shows more or less the same results concerning the distribution of the second dependent variable, post popularity. Again, the median of SFs' post popularity is significantly higher compared to that of LSGBs and FCs.

The following paragraph further elaborates which factors influence the organisations' post popularity.

\subsection{Post popularity (RQ2)}

As described in RQ2, the success factors of post popularity are investigated. All three sectors were examined separately because (from Tables 3 to 5) it can be concluded that each sector has their own accents in terms of SNS usage, and these policies could lead to different outcomes. Below, the results of the linear regressions (see Table 6) are explained.

First, we discuss whether having an account on other SNSs influences the post popularity on Facebook. The presence of a Twitter account influences the post popularity negatively significant for all sectors. For LinkedIn, only the value for SFs is positively significant. There are contradictory results in having an Instagram account for post popularity between SFs and FCs; the beta coefficient for SFs is negative, while this is positive for FCs. Consequently, having an account on Instagram seems to be, taking all 
other independent variables into account, disadvantageous for the post popularity on Facebook for SFs, but advantageous for FCs.

Table 6 Results of the multiple linear regression analysis with post popularity of Facebook as the dependent variable for SFs, LSGBs and FCs

\begin{tabular}{|c|c|c|c|c|c|c|}
\hline \multirow{2}{*}{ Variables } & \multicolumn{2}{|c|}{$S F s$} & \multicolumn{2}{|c|}{$L S G B S$} & \multicolumn{2}{|c|}{$F C s$} \\
\hline & Beta & $t$ & Beta & $t$ & Beta & $t$ \\
\hline Twitter $^{\mathrm{a}}$ & -0.071 & $-2.456^{*}$ & -0.088 & $-2.039 *$ & -0.281 & $-7.373 * * *$ \\
\hline LinkedIn $^{\mathrm{a}}$ & 0.108 & $3.463 * * *$ & -0.016 & -0.342 & 0.030 & 0.770 \\
\hline Instagram $^{\mathrm{a}}$ & -0.137 & $-4.323 * * *$ & 0.036 & 0.736 & 0.189 & $4.848 * * *$ \\
\hline Page popularity & 0.075 & $2.887 * *$ & 0.144 & $3.292 * * *$ & 0.044 & 1.194 \\
\hline \multicolumn{7}{|l|}{ Post frequency } \\
\hline Low & -0.079 & $-2.560 *$ & -0.027 & -0.651 & -0.040 & -1.121 \\
\hline $\begin{array}{l}\text { Medium } \\
\text { High }^{\text {ref. }}\end{array}$ & -0.096 & $-3.020 * *$ & -0.049 & -1.104 & -0.024 & -1.575 \\
\hline \multicolumn{7}{|l|}{ Layout } \\
\hline $\begin{array}{l}\text { Text } \\
\text { Photo }^{\text {Ref. }}\end{array}$ & -0.010 & -0.350 & -0.042 & -0.949 & -0.007 & -0.193 \\
\hline Video & 0.033 & 1.283 & -0.034 & -0.801 & -0.028 & -0.467 \\
\hline Shared post & -0.195 & $-6.933 * * *$ & -0.155 & $-3.361 * * *$ & -0.170 & $-4.268 * * *$ \\
\hline Link & -0.248 & $-7.783 * * *$ & -0.074 & -1.536 & -0.131 & $-3.350 * * *$ \\
\hline \multicolumn{7}{|l|}{ Content } \\
\hline $\begin{array}{l}\text { Atmosphere } \\
\text { photo/video }\end{array}$ & 0.117 & $3.785^{* * *}$ & 0.308 & $6.146^{* * *}$ & 0.244 & $5.476^{* * *}$ \\
\hline Promotions & -0.012 & -0.476 & 0.034 & 0.826 & 0.045 & 1.168 \\
\hline Innovations & 0.024 & 0.930 & 0.129 & $2.989 * *$ & 0.119 & $3.139 * *$ \\
\hline News & 0.072 & $2.757 * *$ & 0.061 & 1.405 & 0.081 & $2.222 *$ \\
\hline Elite sport & 0.241 & $7.816^{* * *}$ & 0.016 & 0.397 & - & - \\
\hline \multicolumn{7}{|l|}{$\begin{array}{l}\text { General } \\
\text { information }^{\text {Ref. }}\end{array}$} \\
\hline Sponsorship/ads & 0.023 & 0.928 & 0.000 & -0.005 & 0.022 & 0.591 \\
\hline Feel-good & 0.139 & $5.103 * * *$ & 0.121 & $2.858^{* *}$ & 0.135 & $2.898 * *$ \\
\hline $\begin{array}{l}\text { Extra-sporty } \\
\text { events }\end{array}$ & -0.007 & -0.281 & 0.003 & 0.075 & 0.057 & 1.500 \\
\hline Check-in posts & - & - & 0.015 & 0.370 & - & - \\
\hline Membership SFb & 0.006 & 0.187 & _ & - & _- & _ \\
\hline $\mathrm{N}$ & $1423 \mathrm{c}$ & 534 & 663 & & & \\
\hline $\mathrm{R}^{2}$ & 0.172 & 0.170 & 0.196 & & & \\
\hline
\end{tabular}

Notes: Levels of significance are ${ }^{*} \mathrm{p}<.05 ; * * \mathrm{p}<.01 ; * * \mathrm{p}<.001 ;$ Ref. $=$ reference category; ${ }^{\mathrm{a} D i c h o t o m o u s ~ v a r i a b l e s ; ~}{ }^{\mathrm{b}}$ memberships are only collected for SFs; ${ }^{\mathrm{c}} \mathrm{SFs}$ whose members are missing are not included. 
Second, page popularity appears to be an important and significant determinant for SFs, as well as for LSGBs. Thus, this variable is also an important control variable.

Third, post frequency is divided into three groups. The 'low' post frequency group consists of one third of the organisations that post the least. Another third of the organisations that have posted the most belongs to the 'high' post frequency group, and the other organisations are part of the 'medium' group. In the multiple linear regression analyses, the 'high' group is the reference category. Only within the SF sector, significant values were found. Moreover, SFs that belong to the 'low' group and the 'medium' group are more likely to have lower post popularity than 'high' post frequency SFs.

Next, the variable layout clearly illustrates that a 'shared post' is significantly negative in comparison with the reference category 'photo' in all three sectors, and thus, it is not ideal to 'share' posts to improve post popularity. This also applies for 'link' as layout, but these results are only significant for SFs and FCs. Note that there is one positive beta coefficient for SFs, namely the layout 'video'. A positive beta coefficient for any layout with reference category 'photo' is not found for LSGBs nor for FCs.

Finally, we take a closer look at the content of the posts. 'general information' is used as a reference category, and Table 6 indicates that 'atmosphere' content, taking all independent variables into account, has a significantly positive influence on post popularity. Furthermore, for SFs the posts about 'news', 'elite sport' and 'feel-good' have shown positive significant results. Although posts about 'innovations' are not significant for SFs, they are for LSGBs and FCs. Also, 'feel-good' posts seemed to be significant for both LSGBs and FCs.

Note that memberships are included as an independent variable for the SFs, but the data showed no significant difference with or without this independent variable.

Naturally, other factors, which are not or cannot be measured, can influence this study's (in)dependent variables and thus account for post popularity. Notwithstanding, the dependent variables accounted for in this study corroborate that post popularity is determined by different factors between the sectors. Moreover, it can be rejected that having a Twitter account has a positive influence on post popularity. On the other hand, having an Instagram account is twofold, as the direction of its influence on post popularity depends on the sector [H3(b)]. For H3(c), having an account on LinkedIn is only advantageous for SFs, since this value is significant. Consistent with H3(d), there is a positive relationship between page popularity and post popularity, thus, significant for LSGBs and FCs. In contrast to H3(e), it can be stated that the increase of post frequency has a positive effect on post popularity for each sector. This is indeed true for all three sectors, whereas this is only significant for 'low' and 'medium' post frequency SFs. H3(f) is true and can be accepted, a 'photo' layout has a truly positive effect on post popularity. At last, $\mathrm{H} 3(\mathrm{~g})$ : posting 'atmosphere' related content to increase post popularity is valid for every sports provider.

\section{Discussion}

Regarding RQ1, the current study indicates that SNS usage is different for each sports provider. Table 3 displays significant results for each independent variable, except for LinkedIn. Prior research from Vos and Scheerder (2014) stipulates that sports providers can be divided into three different clusters, and that they each have their own purposes 
for targeting social (SFs), public (LSGBs) and economic (FCs) profit. This potentially translates into another SNS strategy.

Based on the results of Table 5, the current study indicates which SNS factors produce the highest post popularity or page popularity. Both variables represent 'online success'; page popularity in terms of attracting more fans to 'like' the SNS page and post popularity in terms of liking a post on a page. The findings demonstrate that SFs have the highest page and post popularity, followed by the FCs and the LSGBs. The findings of Table 6 may provide us with an explanation of why SFs and FCs perform rather well and LSGBs do not.

To begin with, the layout type 'photos' are the most frequently used layout, except for SFs. Furthermore, this type of layout positively determines the post popularity. This is in line with the prediction of Miranda et al. (2014) and Thompson et al. (2014) that photos are the most deployed communication vehicles on SNSs, as they are the most personal posting style and are more likely to create fan interaction. Among SFs, 'links' are the most preferred layout (38.9\%). This is parallel with the findings of Wallace et al. (2011), where both NCAA organisations and the big 12 conference athletic departments frequently used links in their communication. Yet, just as 'shared posts', 'links' are less personal and score worse as demonstrated by the results. An explanation for the negative influence of 'sharing' or posting 'links' is that it deflects the user away from the page, i.e., when clicking, the user will be redirected to the web page in question. In addition, they will probably only engage (i.e., 'like' or comment) with the original post/web page. In light of the above, the reason LSGBs have the lowest post and page popularity can be clarified by the fact that they 'share' posts the most.

Secondly, for the variable content, there are also some differences worthy of clarification. For example, $6 \%$ of the Facebook posts of FCs have 'promotion' related content compared to $3 \%$ for SFs and $0.9 \%$ for LSGBs. Following Torben (2010), this study assumed that businesses with a commercial view (e.g., FC) use SNSs more as business/marketing tools. This assumption leads to the expectation of higher 'promotions' posts for FCs than SFs and LSGBs, which is correct according to the results, albeit to only $6 \%$.

This study found 'elite sport' content to be most customarily utilised by SFs (28.2\%). This type of content is an important determinant for SFs, since it is positive for the SFs' post popularity. These results are not illogical, as people often socially identify themselves with athletes (Carlson and Donavan, 2013). This also corresponds to the findings of Wann et al. (2001) which emphasise that communication through media channels has an influence on fan experience. Evidently, trying to attract more members, SFs post a lot about 'their' elite athletes. However, the relationship between elite sport and mass participation is not clear and needs to be relativised (De Bosscher et al., 2013).

Regarding the content, 'atmosphere' and 'feel-good' posts are significantly positive for all three sectors. LSGBs post more 'general information' (41\%) instead of 'atmosphere' (31.3\%), and FCs post more 'feel-good' (38.1\%) as well as 'general information' $(27.9 \%)$. A possible reason for the positive effect for 'feel-good' content could be that these posts are attracting and appealing to everyone. For all sectors, posting the content types 'atmosphere' produce more 'likes' per post. As mentioned above, a personal posting style is the key to success. 'Atmosphere' content posts have mainly a personal touch, and often include subjective feelings, which could be a possible explanation of its post popularity state. Based on Table 3, LSGBs and FCs are not using 
the full potential of this content type. For both sectors a big difference is found, and they would benefit by posting more 'atmosphere photos/videos' to gain more post popularity.

In terms of post frequency, posting with a 'low' or 'medium' frequency has a negative influence on post popularity in comparison with the 'high' posting group, but this is only significant for SFs. Considering the theory of Eagleman (2013), few updates seem to have a negative impact on the post popularity indeed, but the results do not indicate that too many updates are disadvantageous for SNS success. However, additional analyses show that there are only two real outliers in terms of posting: Korfball Flanders and Gymnastics Federation Flanders, which have posted respectively 188 (6.06 a day) and 142 (4.58 a day) times a month. The other SFs post equal to or less than 60 times a month (maximum two posts a day). The high post frequency of Korfball Flanders and Gymnastics Federation Flanders are due to the final national championship games within their sports branch. As stated by social media coordinator Bill Yole, it is not exceptional that the frequency of posts rises during 'game days' as a result of the continuous live updates (Sharpe et al., 2017). Nevertheless, taken into consideration that their post popularity is not high, their post frequency crosses the line of too many updates, in all probability, but in their post frequency group there are also SFs who have posted up to 'only' 30 times. Considering this, posting around one post a day is deemed sufficient.

Finally, prior to this study, little research has focused on the effects of the integral use of SNSs. However, having accounts on other SNSs can have benefits, thus influencing the post popularity positively. Surprisingly, the significant effect for SFs and FCs of having a Twitter account on post popularity is opposite to expectations. A clarification could be that sports organisations mainly focus on one SNS platform to 'share' their posts. Also, each platform requires a proper content marketing strategy. Facebook, for example, requires a different approach than Twitter or Instagram does [Sharpe et al., (2017), p.320] “ $\ldots$ and there is no point putting a picture of lots and lots of text, which is what a news story often is, on Instagram". Maybe if they do opt for both Facebook and Twitter, there is a chance they neglect one platform. Having two platforms requires constant monitoring and updating, which is not easy for many non-profit organisations to manage, since they do not have the budget to employ a social media coordinator (Sharpe et al., 2017).

\section{Conclusions}

The findings from this study revealed:

1 differences between SFs, LSGBs and FCs' SNS usage

2 the success factors of post popularity for these three profit sectors.

Overall, these findings can be used to gain a better understanding of how SNSs operate in a sports context. Eagleman (2013) states that communicating effectively is essential to the survival and growth of sports organisations, and with this study, we have sought to expand the existing research in this field, and to enhance the efficacy of communication amongst sports organisations and their public. Supporting RQ1, there really is a difference between the three sectors concerning SNS usage. Additionally, each sector has its own success factors and thus, policy implications. 
First, this study suggests SFs to post fewer 'links' and 'shared posts', but more 'photos' or 'videos' to gain more post popularity. Additionally, SFs would benefit by choosing between Facebook, Twitter or Instagram as an SNS platform, so they can solely focus on handling one effectively. A recommendation for their content is to keep posting 'elite sport' related posts. SFs have the highest median post and page popularity, which is possible due to the stimulation of using SNSs by the Flemish government. This is expressed via workshops, books (e.g., 'social media for SFs', VSF, 2017), instruction manuals, etc. A SF can also benefit to post more 'feel-good' and 'atmosphere' content.

Secondly, LSGBs use SNS platforms the least effectively, forasmuch as its median page and post popularity. This outcome can be due to the large number of 'shared posts' which are considered ineffective for post popularity. LSGBs should post more 'photos', and it would be better for LSGBs to focus their content more on 'atmosphere', 'innovations' or 'feel-good'.

Lastly, there are some recommendations for FCs. Points for improvement are, same as for LSGBs, to post less 'shared posts' as layout and more 'atmosphere' or 'feel-good' posts as content. Just as the SFs, FCs need to choose one SNS platform, and pay full attention to the one they choose.

\subsection{Limitations and further research}

Certain limitations of the current study need to be mentioned. First, the data collection is conducted over one month, with the SFs being analysed in March 2016, and the LSGBs and FCs in November 2016. Due to the extensive coding work of the objective attribute-based method, it was not possible for the two coders to analyse all the pages of the organisations of the three sectors in one month. However, differences must be acknowledged between the different data gathering periods, since one organisation could, as a result of the nature of the sport, be more active in one period than the other. For example, the SNS usage of Water-ski Flanders, which carry out most of the activities in the summer, may differ during the month of March. Second, this research only examined SNS usage from supply side and the demand side was not considered. Although 'likes' indirectly show the attitude of users towards social media, an in-depth understanding of users' intentions to 'like', comment on, or 'share' a post is not possible from this study. In this regard, Ramadani et al. (2014) investigated, through an expansion of the technological acceptance model (TAM), the behavioural intention of users concerning social media.

The above limitations should be a direction for further research. Further user-focused social media research could lead to new insights. Moreover, research in the form of a survey could clarify what people 'like' on SNSs and which kind of online content they expect from sports organisations. This study mainly covered the popularity of posts in Facebook. For Twitter, Instagram and LinkedIn, this study only analysed the presence of a profile. Since Santana and Hopp (2016) allege that the target audience differs between Facebook and Twitter, and in this light a broader audience can be reached, a deeper understanding on how different SNSs are implemented and used in a marketing communication strategy could be beneficial for sports marketers. 


\section{References}

Abeza, G. and O'Reilly, N. (2014) 'Social media platforms' use of building stakeholder relationships: the case of national sport organizations', Journal of Applied Sport Management, Vol. 6, No. 3, pp.103-126.

Abeza, G., O'Reilly, N., Séguin, B. and Nzindukiyimana, O. (2015) 'Social media scholarship in sport management research: a critical review', Journal of Sport Management, Vol. 29, No. 6, pp.601-618.

Abeza, G., O’Reilly, N., Séguin, B. and Nzindukiyimana, O. (2017) 'Social media as a relationship marketing tool in professional sport: a netnographical exploration', International Journal of Sport Communication, Vol. 10, No. 3, pp.325-358.

Agostino, D. (2013) 'Using social media to engage citizens: a study of Italian municipalities', Public Relations Review, Vol. 39, No. 3, pp.232-234.

Belot, M., Winand, M. and Kolyperas, D. (2016) 'How do international sport federations communicate through social media: a content analysis of FIFA's Twitter communications', in EURAM 2016: Manageable Cooperation?, Paris, 1 June 2016-4 June 2016 [online] http://2016.euramfullpaper.org/program/search.asp?qs=Dimitrios\%20Kolyperas (accessed 11 November 2017).

Bennet, L.V. and Manoharan, A.P. (2016) 'The use of social media policies by US municipalities', International Journal of Public Administration, Vol. 40, No. 4, pp.317-328.

Carlson, B. and Donavan, D. (2013) 'Human brands in sport: athlete brand personality and identification', Journal of Sport Management, Vol. 27, No. 3, pp.193-206.

Carton, S. (2009) Defining Social Media [online] http://www.clickz.com/clickz/column/1703507/ defining-social-media (accessed March 2016).

Chia-chen, Y. and Bradford, B.B. (2013) 'Motives for using Facebook, patterns of Facebook activities, and late adolescents' social adjustment to college', Journal of Youth Adolescence, Vol. 42, No. 3, pp.403-416.

Cohen, J. (1960) 'A coefficient of agreement for nominal scales', Education and Psychological Measurement, Vol. 20, No. 1, pp.37-46.

De Bosscher, V., Sotiriadou, P. and van Bottenburg, M. (2013) 'Scrutinizing the sport pyramid metaphor: an examination of the relationship between elite success and mass participation in Flanders', International Journal of Sport Policy and Politics, Vol. 5, No. 3, pp.319-339.

de Vries, L., Gensler, S. and Leeflang, P.S.H. (2012) 'Popularity of brand posts on brand fan pages: an investigation of the effects of social media marketing', Journal of Interactive Marketing, Vol. 26, No. 2, pp.83-91, SOM Marketing and Som I\&O.

Desmet, N. and Bougrea, A. (2016) Onderzoek Naar het Gebruik van Sociale Media vij Lokale Besturen (Research Into the Use of Social Media Within Local Governments) [online] http://www.vvsg.be/nieuws/Documents/Onderzoeksrapport-2016-sociale-media-gebruik-

lokale-besturen.pdf, http://www.demorgen.be/technologie/deze-emoticons-nemen-het-optegen-de-vind-ik-leuk-knop-b52fe6ea/ (accessed 20 December 2017).

Dexia (2007) Indeling van de Gemeenten in Zestien Clusters op Basis van een Sociaaleconomische Studie (Classification of Municipalities in Sixteen Clusters Based on a Socio-Economic Study) [online] http://regionalestatistieken.vlaanderen.be/sites/default/files/docs/dexia.pdf (accessed 12 February 2017).

Dollinger, M. (2015) 'Social media: cui bono? Who benefits from all this socialness?', Business Horizons, Vol. 58, No. 3, pp.235-236.

Eagleman, A.N. (2013) 'Acceptance, motivations, and usage of social media as a marketing communications tool amongst employees of sport national governing bodies', Sport Management Review, Vol. 16, No. 4, pp.488-497.

Edosomwan, S., Prakasan, S., Kouame, D., Watson, J. and Seymour, T. (2011) 'The history of social media and its impact on business', Journal of Applied Management and Entrepreneurship, Vol. 16, No. 3, pp.79-91. 
Facebook (2017) About Facebook [online] https://www.facebook.com/pg/facebook/about/ (accessed 17 February 2017).

Garcia-Fernandez, J., Elasri-Eijaberi, A., Perez-Tur, F., Triado-Ivern, X.M., Herrera-Torres, L. and Aparicio-Chueca, P. (2017) 'Social networks in fitness centres: the impact of fan engagement on annual turnover', Journal of Physical Education and Sport, Vol. 17, No. 3, pp.1068-1077.

Hailey, L. (2010) The Importance of Social Media Marketing Today [online] https://ezinearticles. com/?The-Importance-of-Social-Media-Marketing-Today\&id=3873989, $\quad \mathrm{http}: / / \mathrm{www}$. socialmediatoday.com/marketing/how-much-time-do-people-spend-social-media-infographic (accessed 11 August 2017).

Hughes, D.J., Rowe, M., Batey, M. and Lee, A. (2011) 'A tale of two sites: Twitter vs. Facebook and the personality predictors of social media usage', Computers in Human Behavior, Vol. 28, No. 2, pp.561-569.

John, L., Emrich, O., Gupta, S. and Norton, M. (2017) 'Does 'liking' lead to loving? The impact of joining a brand's social network on marketing outcomes', Journal of Marketing Research, Vol. 54, No. 1, pp.144-155.

Kaplan, A.M. and Haenlein, M. (2010) 'Users of the world, unite! The challenges and opportunities of social media', Business Horizons, Vol. 53, No. 1, pp.59-68.

Khan, G., Swar, B. and Lee, S. (2014) 'Social media risks and benefits', Social Science Computer Review, Vol. 32, No. 5, pp.606-627.

Kietzmann, J., Hermkens, K., McCarthy, I.P. and Silvestre, B.S. (2011) 'Social media? Get serious! Understanding the functional building blocks of social media', Business Horizons, Vol. 54, No. 3, pp.241-251.

Lee, S. (2011) 'To tweet or not to tweet: an exploratory study of meeting professionals' attitudes toward applying social media for meeting sessions', Journal of Convention and Event Tourism, Vol. 12, No. 4, pp.271-289.

Lovejoy, K., Waters, R. and Saxton, G. (2012) 'Engaging stakeholders through Twitter: how non-profit organizations are getting more out of 140 characters or less', Public Relations Review, Vol. 38, No. 2, pp.313-318.

Mahan, J.E., Seo, W.J., Jordan, J.S. and Funk, D. (2015) 'Exploring the impact of social networking sites on running involvement, running behavior, and social life satisfaction', Sport Management Review, Vol. 18, No. 2, pp.182-192.

McHugh, M.L. (2012) 'Interrater reliability: the kappa statistic', Biochemia Medica, Vol. 22, No. 3, pp.276-282.

Michaelidou, N., Siamagka, N.T. and Christodoulides, G. (2011) 'Usage, barriers and measurement of social media marketing: An exploratory investigation of small and medium B2B brands', Industrial Marketing Management, Vol. 40, No. 7, pp.1153-1159.

Miranda, F.J., Chamorro, A., Rubio, S. and Rodriguez, O. (2014) 'Professional sports teams on social networks: a comparative study employing the Facebook assessment index', International Journal of Sport Communication, Vol. 7, No. 1, pp.74-89.

Mochon, D., Johnson, K., Schwartz, J. and Ariely, D. (2017) 'What are likes worth? A Facebook page field experiment', Journal of Marketing Research, Vol. 54, No. 2, pp.306-317.

Naraine, M.L. and Parent, M.M. (2016) 'Illuminating centralized users in the social media ego network of two national sport organizations', Journal of Sport Management, Vol. 30, No. 6, pp.689-701.

Neuendorf, K.A. (2002) The Content Analysis Guidebook, Sage, Thousand Oaks, CA.

Newson, A., Houghton, D. and Patten, J. (2009) Blogging and Other Social Media: Exploiting the Technology and Protecting the Enterprise, 2nd ed., Routledge, London.

Ngai, E., Tao, S. and Moon, K. (2014) 'Social media research: theories, constructs, and conceptual frameworks', International Journal of Information Management, Vol. 35, No. 1, pp.33-44. 
Parganas, P., Anagnostopoulos, C. and Chadwick, S. (2015) 'You'll never tweet alone': managing sports brands through social media', Journal of Brand Management, Vol. 22, No. 7, pp.551-568.

Paridon, T. and Carraher, S.M. (2009) 'Entrepreneurial marketing: customer shopping value and patronage behaviour', Journal of Applied Management and Entrepreneurship, Vol. 14, No. 2 , pp.3-28.

Pegoraro, A. (2014) 'Twitter as disruptive innovation in sport communication', Communication and Sport, Vol. 2, No. 2, pp.132-137.

Pinto, M. and Yagnik, A. (2017) 'Fit for life: a content analysis of fitness tracker brands use of Facebook in social media marketing', Journal of Brand Management, Vol. 24, No. 1, pp.49-67.

Pletikosa Cvijikj, I. and Michahelles, F. (2013) 'Online engagement factors on Facebook brand pages', Social Network Analysis and Mining, Vol. 3, No. 4, pp.843-861.

Pronschinske, M., Groza, M.D. and Walker, M. (2012) 'Attracting Facebook 'fans': the importance of authenticity and engagement as a social networking strategy for professional sport teams', Sport Marketing Quarterly, Vol. 21, No. 4, pp.221-231.

Rahman, Z., Suberamanian, K. and Zanuddin, H. (2016) 'Social media content analysis: a study on fan pages of electronics companies', International Journal on Global Business Management and Research, Vol. 5, No. 1, pp.87-96.

Ramadani, V., Demiri, A. and Saiti-Demiri, S. (2014) 'Social media channels: the factors that influence the behavioural intention of customers', International Journal of Business and Globalisation, Vol. 12, No. 3, pp.297-314.

Ratten, V. (2011) 'Sport-based entrepreneurship: towards a new theory of entrepreneurship and sport management', International Entrepreneurship and Management Journal, Vol. 7, No. 1, pp.57-69.

Reyneke, M., Pitt, L. and Berhton, P.R. (2011) 'Luxury wine brand visibility in social media: an exploratory study', International Journal of Wine Business Research, Vol. 23, No. 1, pp.21-35.

Roohani, S. and Attaran, S. (2013) 'Social media: new challenges and opportunities for corporate governance', International Journal of Disclosure and Governance, Vol. 11, No. 4, pp.366-379.

Sabate, F., Berbegal-Mirabent, J., Canabate, A. and Lebherz, P.R. (2014) 'Factors influencing popularity of branded content in Facebook fan pages', European Management Journal, Vol. 32, No. 6, pp.1001-1011.

Santana, A.D. and Hopp, T. (2016) 'Tapping into a new stream of (personal) data', Journalism and Mass Communication Quarterly, Vol. 93, No. 2, pp.383-408.

Scheerder, J. and Vos, S., with the cooperation of Breesch, D., Lagae, W. and Van Hoecke, J. (2010) De Fitnesssector in Beeld: Basisrapportering over Het Vlaamse Fitness Panel 2009 (VFP09) (The Fitness Sector in the Picture: Basic Reporting on the Flemish Fitness Panel 2009) (Sport Policy and Management 3), KU Leuven/Policy in Sports and Physical Activity Research Group, Leuven.

Scheerder, J., Zintz, T. and Delheye, P. (2011) 'The organisation of sports in Belgium: between public, economic and social profit', in Sobry, C. (Ed.): Bookseries: Sport Social Studies, Sports Governance in the World: a Socio-Historic Approach, The Organization of Sport $i$ Europe: A Patchwork of Institutions, with Few Shared Points, pp.84-113, Le Manuscrit, Paris.

Schonfeld, E. (2007) Liveblogging Facebook Advertising Announcement (Social Ads + Beacon + Insights) [online] https://techcrunch.com/2007/11/06/liveblogging-facebook-advertisingannouncement/ (accessed June 2016).

Schubert, M. and Seyffert, J. (2017) 'Fan motives for interacting on social media: the example of the international table tennis federation and Facebook', Current Issues in Sport Science, Vol. 2, No. 4, DOI: 10.15203/CISS_2017.004. 
Schultz, C. (2016) 'Driving likes, comments, and shares on social networking sites: how post characteristics affect brand interactions in apparel retailing', Proceedings of the 18th Annual International Conference on Electronic Commerce, pp.1-9.

Seng, C. and Keat, L. (2014) 'Marketing sports products on Facebook: the effects of social influence', Physical Culture and Sport, Vol. 61, No. 1, pp.65-73.

Sharpe, S., Kunkel, T., Scott, O. and Beaton, A. (2017) 'Managing digital content for a professional sport team: an overview with Bill Yole, social media coordinator and webmaster of the ACT brumbies super rugby franchise', International Journal of Sport Communication, Vol. 10, No. 3, pp.318-324.

Shinder, D. (2012) 'Properly using social networking sites', Agency Sales, Vol. 42, No. 8, pp. $22-25$.

Statista (2017) Number of Social Media Users Worldwide From 2010 to 2021 [online] https:// www.statista.com/statistics/278414/number-of-worldwide-social-network-users/ (accessed 20 November 2017).

Thompson, A.J., Martin, A., Gee, S. and Eagleman, A.N. (2014) 'Examining the development of a social media strategy for a national sport organisation: a case study of Tennis New Zealand', Journal of Applied Sport Management, Vol. 6, No. 2, pp.43-62.

Torben, R. (2010) How to Use Social Media for Change Management [online] http://www. torbenrick.eu/blog/change-management/how-to-use-social-media-for-change-management (accessed 26 December 2016).

van Poppel, M., Scheerder, J. and Vandermeerschen, H. (2016) 'Sportdiensten in beeld: Resultaten van het Vlaamse Sportdienst Panel 2.0 (VSDP2.0)', (Local sports governing bodies in the picture: Results from the Flemish Local Sports Governing Bodies Panel 2.0), Policy \& Management in Sport Studies 24, KU Leuven/Policy in Sport \& Physical Activity Research Group, Leuven.

Vos, S. and Scheerder, J. (2014) 'Fact or fiction? An empirical analysis of cooperation between mass sport providers at the local level', European Journal for Sport and Society, Vol. 11, No. 1, pp.7-34.

VSF (2017) Federaties (Federations) [online] https://www.vlaamsesportfederatie.be/federaties (accessed 15 January 2017).

Wallace, L., Wilson, J. and Miloch, K. (2011) 'Sporting Facebook: a content analysis of NCAA organizational sport pages and big 12 conference athletic department pages', International Journal of Sport Communication, Vol. 4, No. 4, pp.422-444.

Wann, D.L., Ensor, C.L. and Bilyeu, J.K. (2001) 'Intrinsic and extrinsic motives for originally following a sport team and team identification', Perceptual and Motor Skills, Vol. 93, No. 2, pp.451-454.

Waters, R.D., Burnett, E., Lamm, A. and Lucas, J. (2009) 'Engaging stakeholders through social networking: how non-profit organizations are using Facebook', Public Relations Review, Vol. 35, No. 2, pp.102-106.

Watson, P. and Petrie, A. (2010) 'Method agreement analysis: a review of correct methodology', Theriogenology, Vol. 73, No. 9, pp.1167-1179.

Williams, J., Chinn, S.J. and Suleiman, J. (2014) 'The value of Twitter for sports fans', Journal of Direct, Data and Digital Marketing Practice, Vol. 16, No. 1, pp.36-50.

Witkemper, C., Lim, C.H. and Waldburger, A. (2012) 'Social media and sports marketing: examining the motivations and constraints of Twitter users', Sport Marketing Quarterly, Vol. 21, No. 3, pp.170-183.

\section{Notes}

1 Kruskal-Wallis test was conducted since a Shapiro-Wilk test $(\mathrm{p}<.001)$ demonstrated that both dependent variables (i.e. Post and Page Popularity) are not normally distributed. 